\title{
Structural and geomechanical models of gold deposits in the Amur region (Russia)
}

\author{
Igor Rasskazov ${ }^{1}$, Viktor Kryukov ${ }^{1 *}$ and Marina Potapchuk ${ }^{1}$ \\ ${ }^{1}$ Mining Institute FEB RAS, 51 Turgenev st., Khabarovsk, 680000, Russia
}

\begin{abstract}
A large number of gold deposits are concentrated in the Russian part of the Amur river basin. Gold units are characterized by various formation conditions, and, due to this, by a variety of structural factors, as well as stability of rock masses. Structural features, qualities and properties of ore-bearing rocks determine the specifics of choosing mining systems for the units. Geological and geomechanical data obtained in the course of exploration and exploitation of objects allowed us to identify groups of deposits with similar genetic conditions and form common features of their development through the development of appropriate models. There are five major groups of gold deposits. They are represented by deposits formed in epiplatform conditions of young volcanism, in intrusive-tectonic and intrusive-dome structures of Cretaceous age, in metamorphic domes, as well as in tectonic wedges. The selected groups of deposits are localized in masses with different rock stability. In accordance with these features, we developed structural and geomechanical models of gold deposits in the Amur region. The models are used for correcting the methodology of studying deposits and justifying rational methods of their development.
\end{abstract}

\section{Introduction}

The purpose of the study is to form models of gold deposits depending on the stability of the host rock mass and the structure of the unit, which determine the choice of optimal systems and conditions for development.

The choice of two factors - the structure of the deposit and the physical and mechanical properties of rocks - is primarily due to their dominant role in the justification of the mining system. Therefore, when calculating the main elements of the quarry, the endogenous fracturing, its parameters and angles of occurrence determine the size of ledges, angles of slopes and other features of the internal structure of the quarry. At the same time, we classify both actual fracturing and disjunctions of various types (crumpling, splitting, cataclase, mylonitization, etc.) as endogenous fracturing. Undoubtedly, when designing a quarry, the morphology of ore bodies, the nature of the distribution of ore mineralization, as well as the strength of ore-bearing rocks and the ores themselves all play a great role.

\footnotetext{
*Corresponding author: kryukov-vg@mail.ru
} 


\section{Situation analysis, problem statement}

The south of the Russian Far East is known for its gold content. At the same time, gold-ore units are characterized by different conditions of formation and, due to this, a variety of structural factors and stability of the rock mass. The study of territories and ore occurrences in the process of geological survey, search and exploration, as evidenced by practice, is most often specialized in certain minerals and certain features of the geological structure of areas and specific sites [1]. This leads to the accumulation of peculiar information, which usually does not provide completeness and objectivity. For example, since the time of the 1:200,000 scale geological survey, a certain viewpoint has formed about the active blockand ore-controlling (and ore-bearing) role of long-lived faults of the North-Eastern orientation. From all the physical and mechanical properties of rocks, geologists studied mainly the volume weight and strength of rocks for abrasion. Such materials can certainly not serve as a basis for the design of a mining enterprise.

The general problem of deposit mining is not only the completeness of the information required for calculating the conditions of their development, but also the need for a theoretical justification of the choice of the operating system. This justification is obtained from the analysis of specialized structural and geomechanical models of objects [2].

It should be noted that many researchers provide diagrams of the geological structure of the majority of gold deposits in the Amur region, which can be used to some extent in the development of their structural models. A particularly complete information about the structural factors of ore localization is contained in the Atlas of multi-factor models of gold deposits, developed by a team of authors under the supervision by A.P. Van-Van-E [3]. The Atlas was compiled at the end of the last century on the basis of search and exploration materials. Geomechanical features of rock masses were not considered by geologists for this. These aspects are discussed on the example of a number of large and medium-sized deposits of the Amur region involved in development at the beginning of this century [4-6]. It is necessary to emphasize the use of not only geological exploration materials, but also their own observations in quarries and underground workings.

It is possible to obtain full information about the deposit if research organizations are actively involved in its study at all stages of geological exploration. In scientific terms, the development of the models is the final link in the study of deposits.

Methodically, our research consisted of the following. We studied the core of 2-3, sometimes 5-7 wells at the fields. Special attention was paid to the diagnostics of rocks and ores, the composition and zoning of metasomatites, and also structural features. The quantitative assessment of the properties and quality of rocks was carried out in the following categories: initial rocks (up to 5\% of new formations), slightly modified (6-15\%), moderately modified (16-30\%), modified (31-50\%), intensely modified or fully manifested metasomatites (51-95\%) and cavity metasomatites (more than 95\%). The same gradation was used to characterize various structures (zones of fracturing, crumpling, splitting, flaring, mylonitization, etc.).

An important part of the work is the analysis of photographic documentation of well cores, in which our documentation of the core and subsequent analysis of photographic documentation of the core of these wells served as a standard in the diagnosis of the core of the remaining wells. Photographic documentation of the core of dozens of wells (from 1.52 to 8-12 lin $\mathrm{km}$ ) was studied for each of the objects. Rocks, metasomatites, veined and veinlet-disseminated formations, sulfide mineralization, as well as cracks and destruction zones were read from the photo documentation. As a result, we identified groups of rocks and determined physical and mechanical properties of the rocks of the mass in laboratory setting (density by float method, uniaxial compression and stretching on the ToniNORM equipment, etc.). 
The obtained original material is used as the basis for identifying typical structural settings and formation of appropriate structural and geomechanical models of ore units. The grouping of units based on structural features and properties of rocks is determined by a number of factors: the depth of formation (structural groups), the structural framework determined by a combination of pre-ore and sin-ore violations (structural types), the spatial position of rock blocks with different physical and mechanical properties. The morphology of ore bodies and the properties of the rock mass also affect the attribution of objects to a particular type [7]. In accordance with this approach, it is advisable to combine the gold deposits of the Amur region into five groups: formed in epiplatform conditions of young volcanism, in intrusive-tectonic and intrusive-dome structures of Cretaceous age, in metamorphic domes, as well as in tectonic wedges. The selected groups of deposits are localized in masses with different rock stability.

\section{Results and discussion}

Deposits formed in the epiplatform conditions of Cenozoic volcanism are characterized by a fairly high stability of rock masses. Common characteristics of such deposits are localized within stratovolcanoes, preferential attachment to the side apparatus; the covers of basalts, andesites and their tuffs have a low sedimentation and weak tectonic disturbances; moderate degree of fracturing of rocks, from 1-3 to 5-8 cracks per 1 linear meter; virtually homogeneous the distribution of values of disturbance within the deposit; variations of physico-mechanical properties of rocks characteristic of orifice parts of volcanoes; the relative uniformity of composition of ore-bearing rocks; significant volumes of metasomatic formations, which differ from host rocks by significant decompaction in the processes of potassic alteration, sericitization and hydromication of educts; we should also note the presence in the internal structure of the unit of cores, the intermediate ore-bearing zone and the peripheral part characterized by the development of carbonate and quartz-carbonate veinlets. The "cores" are usually composed of hydrothermal quartzites, the most durable of all the deposit's rocks. In the ore-bearing zone we observed argillisites, quartz-adulatory metasomatites.

Such deposits include Belaya Gora, Bukhtyanskoye, Blagodatnenskoye, Kabachinskoye, Polyanka, and a number of ore occurrences located in the Lower Amur region of the Khabarovsk territory [8].

The marked structural features are fully recorded within the Belaya Gora deposit.

Deposits located within intrusive-tectonic structures represent a fairly large group of objects. They are characterized by the following features: they are confined to local ring structures formed at the intersection of submeridional and sublatitudinal tectonic disturbances. The main distinctive features of this group of deposits: the manifestation of subsidence processes in relation to the frame by annular disjunctions and the prevailing role of sedimentary rocks; moderate and medium degree of fracturing of the rock mass, from 8-10 to 15-20 cracks per 1 linear meter; mosaic distribution of blocks with different rock stability; a large variety of rocks containing mineralization; sedimentary formations are collected in steep folds, and intrusive bodies have a very variegated composition and mostly steep bedding. Small intrusive masses and stocks, in general, do not have inlet channels; significant amounts of ore-metasomatic formations, which differ from host rocks by significant decompaction in the processes of albitization, actinolitization and hydromication of educts; in the internal structure of objects, we should note the presence of "cores" composed of quartz-illite (hydromicaceous) metasomatites, ore-bearing intermediate (beresites, actinolite, carbon metasomatites) and peripheral (propylites) parts of structures.

This group includes deposits and occurrences of Albazino, Agnie-Afanas'evskoe, Diappe, Zimovye, Kutyn, Pokrovsko-Troitskoe, and Prognoznoe. 
The Diappe deposit is considered as a reference in this group, since it most fully embodies the described structural features [6]. The area of the deposit is composed of sedimentary rocks of Cretaceous age, broken by gabbro stocks and dikes, diorites and granodiorites, as well as their porphyritic differences.

Deposits located within intrusive dome structures of various sizes represent the largest group of objects. They are characterized by the following features: localization within intrusive dome structures confined to the intersection points of submeridional and sublatitudinal tectonic disturbances with steep, medium and shallow angles of incidence. Ring structures are characterized by processes of uplifting, doming; the prevailing role of intrusive rocks of moderate-acidic and medium compositions; moderate and medium degree of fracturing of the rock mass, from 5-7 to $12-15$ cracks per 1 linear meter; mosaic distribution of blocks with different rock stability; intrusive bodies have both steep and flat bedding; a large variety of rocks that contain mineralization; significant volumes of ore-metasomatic formations that differ from the host rocks by significant decompaction in the processes of potassic alteration, sericitization and hydromication of educts; in the internal structure of objects, we should note the presence of "cores" composed of quartz-hydrosluidic or quartzhydromicaceous metasomatites, intermediate ore-bearing (beresites, orthoclazites, including orthoclase-biotite metasomatites, quartz-tourmaline, quartz-carbon formations) and peripheral (propylites) parts of structures.

This group includes the deposits and occurrences of Pionernoe, Pokrovskoe

The Pionernoe deposit is considered as a reference for this group because it is the most studied structurally. The area of the deposit is composed mainly of Cretaceous granitoids. Within the ore field, we studied the ore zones Andreevskaya, Bakhmut, and Nikolaevskaya, each of which, in essence, represents an independent deposit.

Deposits that are localized in metamorphic domes of regional schistosity zones have a relatively moderate prevalence. They clearly differ from the units of other groups in their structural and geomechanical features, which are as follows: they are confined to regional faults of considerable power and, as a rule, have steep angles of incidence. In local termslocalization in metamorphic domes; metamorphic domes Malomyrsky, Kharginsky, Tokursky, despite the similarity in structure, differ from each other in the scale of granitization, the intensity of schistosity, the composition and parameters of near-ore metasomatites, which affects the physical and mechanical characteristics of rocks; a high degree of fracturing of the rock mass, 18-20 or more cracks per 1 linear meter; noticeable fragility of rocks, in contrast to other groups of deposits; moderate saturation with intrusive bodies and, therefore, a simpler composition of host rocks; ore-metasomatic formations are similar in their physical and mechanical properties to host rocks.

The marked group represented by deposits and ore occurrences Ubinskoe, Afanas'evskoe, Ingalinskoe, Malomyrskoe, Sagurskoe, Tokurskoe, Kharginskoe.

The reference for this group is the Malomyrskoye deposit (table 1). The area of the Malomyrskoye deposit is composed of various shales of quartz-feldspar, quartz-mica, quartz-feldspar-chlorite composition, broken by dikes of basalts, andesites and dacites. In the northern part of the ore field, in the Quartzite section, we can observe block granitization of shales.

Deposits located in tectonic wedges are moderately common. They clearly differ from the units of other groups in their structural and geomechanical features, which are as follows:

- confined to regional faults of considerable power and, in general, having steep angles of incidence. Locally - the localization in intrusive-tectonic structures, which causes a certain similarity with the deposits of group 2;

- high degree of fracturing of the rock mass, 15-20 or more cracks per 1 linear meter; 
- moderate saturation of intrusive bodies and, therefore, a simpler composition of the host rocks;

- relative homogeneity of the rock mass in terms of their stability;

- ore-metasomatic formations are similar in their physical and mechanical properties to the host rocks;

- the structure of the deposit is close to the structure of group 2 units.

Representatives of this group are Delken and Poniyskoe gold-copper-porphyry deposit.

The Delken deposit, considered as a reference, is located within a folded structure composed of sandstones and argillites of Triassic-Jurassic and Jurassic age. Sedimentary rocks are intruded by dikes of spessartites, as well as stock and dikes of fluidolites. The tectonic wedge is caused by the intersection of faults of the submeridional and north-eastern orientation.

\section{Conclusion}

We can conclude that the observations on a sufficiently large number of objects in the Amur region establish a pattern that structural factors and geomechanical features of rock masses are the main factors in the choice of a mining system. Gold-mining objects of the Amur region are characterized by different conditions of formation and the resulting diversity of the structure of deposits, as well as physical and mechanical properties of rocks. These features allow us to identify similarities and differences and reflect them in field models.

Despite the individuality of each deposit, there are 6-8 features in the structure of the ore field, the morphology of ore bodies, the nature of fracturing and other properties of the rock mass, which establish common features for subsequent grouping. There are five groups of objects that are localized in various geostructural settings. In each group of isolated structural-mechanical types, the references of which are Belaya Gora, Diappe, Pionernoe, Malomyrskoe and Delken gold deposits.

Structural and geomechanical models of reference deposits are presented in tabular form (table 1). The main elements of the table are the characteristics of the main parameters (structure, fracturing, physical and mechanical properties of rocks, mining conditions, etc.) and the geological and structural scheme of the deposit. The model can be used for operational management of mining operations. 
Table 1. Model of Malomyrskoe deposit

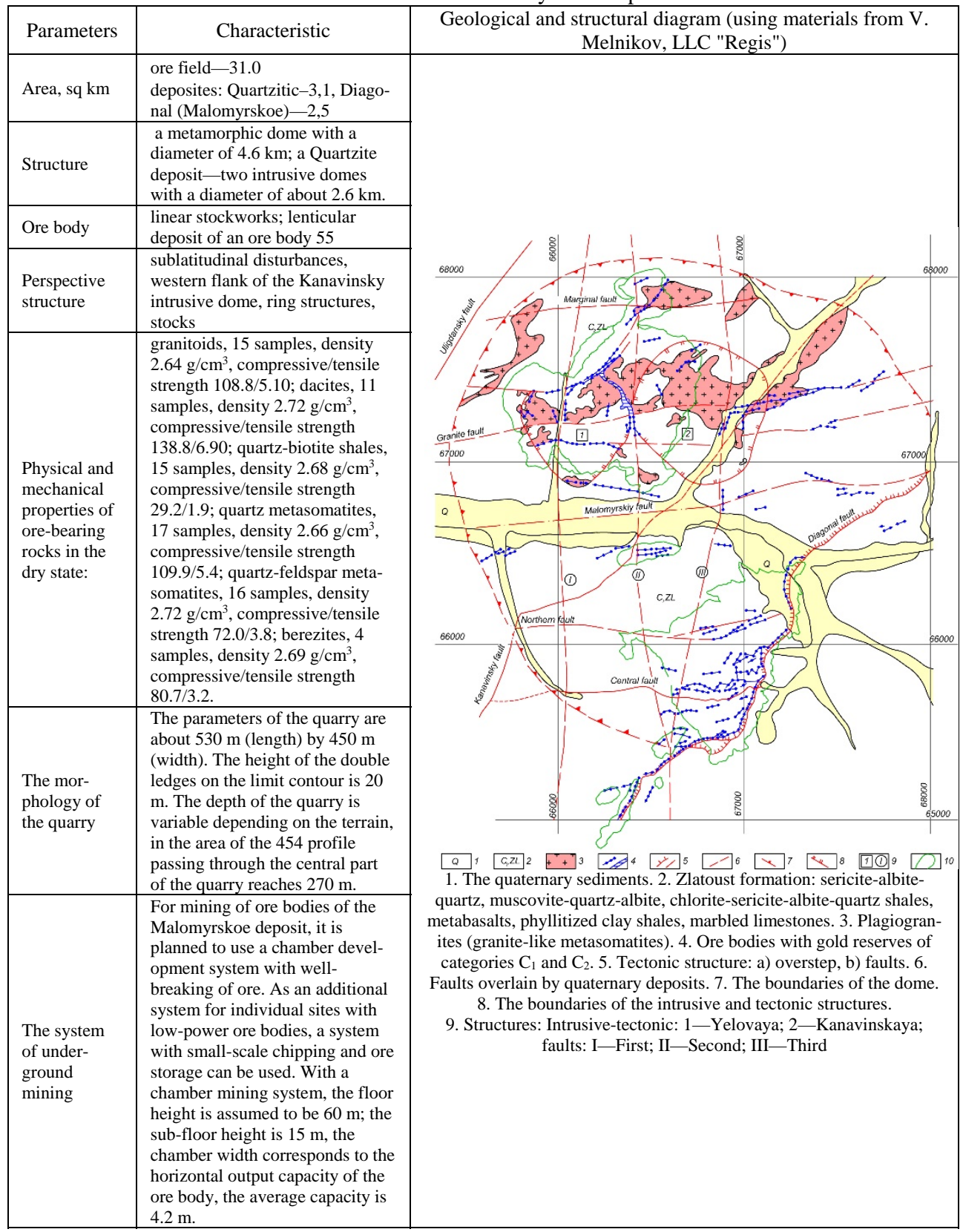




\section{Literature}

1. A.P. Prokofiev, Fundamentals of prospecting and exploration of deposits of solid minerals (Moscow: Nedra, 1973)

2. Emmanuel John M. Carranza, Ore Geology, 35(3-4), 383-400 (2009). doi.org/10.1016/j.oregeorev.2009.01.001

3. A.P. Van-Van-E, I.S. Peltsman, E.A. Orlova, V.G. Nevstruev, L.V. Eirish, Atlas of multi-factor models of gold deposits in the Far East (Khabarovsk: ZHASO-Amur. 2000)

4. I.Yu. Rasskazov, V.G. Kryukov, M.I. Potapchuk, A.V. Sidlyar, Surveying and subsurface use, 5, 52-58 (2018)

5. I.Yu. Rasskazov, V.G. Kryukov, B.G. Saksin, M.I. Potapchuk, Mining information and analytical bulletin. 11(special issue 24), 7 (2017)

6. V.G. Kryukov, M.I. Potapchuk, Mining information and analytical bulletin. 11(special issue 24), 364-372 (2017)

7. Xi-An Yang, Jie Wu, Ian M. Coulson, Jinzhang Zhang, Xiaodan Lai, Yabin Zhang, Deru Xu, Jiajun Liu, Guangrong Li, Hualiang Li, Ore Geology, 118, 103216 (2020) doi.org/10.1016/j.oregeorev.2019.103216.

8. N.S. Ostapenko, O.N. Neroda, International research journal 12(90), 1, 148-153. DOI: 10.23670/IRJ.2019.90.12.029 